\title{
From model intercomparison toward benchmark UV spectra for six real atmospheric cases
}

\author{
M. van Weele, ${ }^{1}$ T. J. Martin, ${ }^{2,3}$ M. Blumthaler, ${ }^{4}$ C. Brogniez, ${ }^{5}$ P. N. den Outer, ${ }^{6}$ \\ O. Engelsen, ${ }^{7}$ J. Lenoble, ${ }^{5}$ B. Mayer, ${ }^{8,9}$ G. Pfister, ${ }^{10}$ A. Ruggaber, ${ }^{11}$ B. Walravens, ${ }^{12}$ \\ P. Weihs, ${ }^{13}$ B. G. Gardiner, ${ }^{2}$ D. Gillotay, ${ }^{12}$ D. Haferl, ${ }^{4}$ A. Kylling, ${ }^{14}$ \\ G. Seckmeyer, ${ }^{8}$ W. M. F. Wauben ${ }^{1}$
}

\begin{abstract}
The validity of a radiative transfer model can be checked either by comparing its results with measurements or with solutions for artificial cases. Unfortunately, neither type of comparison can guarantee that the spectral UV surface irradiance is accurately calculated for real atmospheric cases. There is a need therefore for benchmarks, i.e., standard results that can be used as a validation tool for UV radiation models. In this paper we give such benchmarks for six cloud-free situations. The chosen cases are characterized by different values of solar zenith angle, ozone column, aerosol loading, and surface albedo. Observations are also available for these cases to allow a further comparison between model results and measurements. An intercomparison of 12 numerical models is used to construct the benchmarks. Each model is supplied with identical input data, and a distinction is made between models that assume a planeparallel geometry and those that use a pseudospherical approximation. Differences remain between the model results, because of different treatments of the input data set.

Calculations of direct and global transmission and direct and global irradiance are within $3 \%$ for wavelengths longer than $320 \mathrm{~nm}$. For the low-Sun cases the calculations are within $10 \%$ for wavelengths longer than $300 \mathrm{~nm}$. On the basis of these calculations, six benchmark UV spectra $(295-400 \mathrm{~nm})$ are established with a standard deviation of $2 \%$. Relative standard deviations are higher for the lowest absolute intensities at low Sun (5\% at $300 \mathrm{~nm}$ ). The variation between models is typically less than the variation seen between model and measurement. Differences between the benchmarks and the observed spectra are mainly due to the uncertainty in the input parameters. In four of the six cases the benchmarks agree with the observed spectra within $13 \%$ over the whole UV spectral region.
\end{abstract}

\section{Introduction}

In this paper we compare 12 radiative transfer models that are used in various institutes throughout Europe to calculate the surface solar spectral UV irradiance. For this study all

\footnotetext{
${ }^{1}$ Royal Netherlands Meteorological Institute, De Bilt.

${ }^{2}$ British Antarctic Survey, Cambridge, England.

${ }^{3}$ Now at the Fraunhofer Institute for Atmospheric Environmental Research, Garmisch-Partenkirchen, Germany.

${ }^{4}$ Institute of Medical Physics, University of Innsbruck, Innsbruck, Austria.

${ }^{5}$ Université des Sciences et Technologies de Lille, Villeneuve d'Ascq, France.

${ }^{6}$ National Institute of Public Health and the Environment, Bilthoven, Netherlands.

${ }^{7}$ NORUT Information Technology, Troms $\emptyset$, Norway.

${ }^{8}$ Fraunhofer Institute for Atmospheric Environmental Research, Garmisch-Partenkirchen, Germany.

${ }^{9}$ Now at the National Center for Atmospheric Research, Boulder, Colorado.

${ }^{10}$ Institute for Meteorology and Geophysics, University of Graz, Graz, Austria.

${ }^{11}$ Meteorological Institute, University of Munich, Munich, Germany.

${ }^{12}$ Belgian Institute for Space Aeronomy, Brussels.

${ }^{13}$ Institute of Meteorology and Physics, Universitaet fuer Bodenkultur, Vienna, Austria.

${ }^{14}$ Norwegian Institute for Air Research, Kjeller, Norway.

Copyright 2000 by the American Geophysical Union.

Paper number 1999JD901103.

0148-0227/00/1999JD901103\$09.00
}

codes are run with a common set of atmospheric and surface descriptors. A comparison is made with respect to the mean of the model calculations. To ensure that the results are meaningful, and to gain further information on the ability of models to reproduce values of surface UV irradiance, the model results are also compared with actual surface measurements. On the basis of the results of the model intercomparison we construct benchmarks for six well-defined cases. These six benchmarks, together with their uncertainty ranges, can serve as a validation tool for numerical models that simulate UV spectra at the Earth's surface. The model intercomparison described in this paper is an integral part of the project SUVDAMA (Scientific Ultra-Violet Data Management), the overall goal of which is to initiate a scientific interpretation of the existing ground-based spectral UV measurements in Europe by means of close interaction between the modeling and the measuring scientific communities.

Several groups involved in SUVDAMA have a radiation code, which they use for analyzing their spectral irradiance measurements. The objective of this paper is to intercompare these codes, as they are usually run, using the best (and always limited) ancillary data as input parameters, and to compare the model results with actual irradiance measurements. The paper shows that the interpretation of ancillary measurements such as aerosol optical depth and total ozone, which are often performed simultaneously with irradiance measurements, can lead to differences in the calculated spectra. 
Koepke et al. [1998] recently published an intercomparison of UV index calculations, but the approach of the present model intercomparison differs in several respects from this. Here the number of cases considered is limited to just six examples which between them cover typical ranges of solar elevation, ozone column, surface albedo, and aerosol loading. The intercomparison is performed for the (direct and global) irradiance and transmission at high spectral resolution. The input specifications to the models are constrained more strictly. Furthermore, the goal of the present intercomparison is the construction of benchmark spectra rather than the calculation of a UV index.

Several methods are available for solving the equation of radiative transfer in a plane-parallel atmosphere. Some methods, although mathematically elegant, are limited to artificial cases, such as a homogeneous atmosphere with isotropic (or slightly anisotropic) scattering; this is the case for the method based on $X$ and $Y$ functions. In these simple cases the results of radiative transfer calculations can agree to within five significant figures [Benassi et al., 1984], which clearly far exceeds the accuracy necessary for most atmospheric applications. More approximate treatments, such as the two-stream solution, have also been widely used and remain useful for rapid computations; their degree of uncertainty depends strongly both on the characteristics of the atmosphere and on the radiometric quantity required (e.g., the radiance or irradiance at the top or bottom of the atmosphere).

Most numerical methods can be extended to treat vertically inhomogeneous atmospheres, built from a number of homogeneous layers, and to encompass any scattering law. Among the most popular numerical methods are discrete ordinates, spherical harmonics, successive orders of scattering, the FN method based on eigenfunctions, doubling-adding, and the matrix operator method. A brief description of different methods can be found in the works of Van de Hulst [1980] and Lenoble [1985]. Lenoble also gives tabulated results for simple cases, and these have been used as benchmarks by many authors for checking their codes. Highly constrained layer-bylayer solutions to the equation of radiative transfer can also be found in the works of Stamnes and Conklin [1984] and Garcia and Siewert [1985]. These solutions provide rigorous tests for the numerical methods but do not correspond to realistic terrestrial atmospheres.

Uncertainties arise in model calculations for various reasons. Approximations are introduced into the numerical procedure by the use of only a finite number of direction, wavelength, and altitude variables. A compromise must be found between the precision and the computational burden. Additional uncertainties are introduced in the process of moving from a description of an atmosphere to the values of the optical parameters passed to the equation of radiative transfer. An atmosphere is typically defined in terms of pressure and temperature profiles, with further information provided on the optical depth, composition, and vertical distribution of aerosol and cloud particles. These variables must be converted to values of extinction coefficient, single-scattering albedo, and a scattering phase function. The details of this conversion procedure differ from one model to the next. For example, in replacing the real atmosphere by a superposition of homogeneous layers, the number and position of these layers, and the value of the constant parameters within them, is a somewhat arbitrary choice. The physical data used in the models, such as the absorption cross sections of ozone, the Rayleigh scattering cross sections and the extraterrestrial spectrum depend on which data set is chosen. The procedures used to interpolate any of these variables may differ from one model to another. The measurement uncertainties in these physical data are also important when considering comparisons between models and measurement. Finally, there is always the possibility that any model may contain an error. Our intercomparison includes this type of uncertainties in the codes and does not aim at comparing numerical solution methods to the radiative transfer equation.

Among the 12 codes compared here, eight are based on the discrete-ordinates method, applied in an environment defined by each modeler. Other codes use the doubling-adding, the matrix-operator, the successive-scattering, and the two-stream methods. Table 1 summarizes the codes and their methods as used in this paper. Also indicated is if a code is run with pseudospherical (PS) corrections. Pseudospherical corrections imply that the sphericity of the Earth's atmosphere is taken into account in the treatment of the direct radiation, i.e., for the directly transmitted radiation from the Sun and also for the direct radiation contributing to the scattering source function. Note that full spherical corrections, as opposed to pseudospherical corrections, would imply that the Earth's sphericity is also taken into account in the radiative transfer of the scattered radiation. None of the codes used in this paper is run in full spherical geometry.

Firstly, we compare the spectral transmissions (direct and global) and surface irradiances (direct and global) determined by the models, and secondly, we compare model spectra of global irradiance with measurements. The model results of (direct) transmission facilitate finding the explanations for the differences between the calculations. We choose six cloud-free cases, each characterized by different values of solar zenith angle, ozone column, aerosol loading, surface albedo, and surface elevation: two cases in Ispra $\left(45.82^{\circ} \mathrm{N}, 8.63^{\circ} \mathrm{E}, 214 \mathrm{~m}\right)$, three in Garmisch-Partenkirchen $\left(47.48^{\circ} \mathrm{N}, 11.07^{\circ} \mathrm{E}, 730 \mathrm{~m}\right)$, and one in De Bilt $\left(52.10^{\circ} \mathrm{N}, 5.18^{\circ} \mathrm{E}, 17 \mathrm{~m}\right)$. The spectra of the cases in Ispra are reference spectra constructed from measurements made during an intercomparison of spectroradiometers in May 1995. The construction of these reference spectra from the various measured spectra is described in detail by Gardiner and Kirsch [1997].

Comparison of the model results with actual UV irradiance measurements raises the problem of choosing values for the model input parameters that are close to the actual atmospheric parameters at the place and time of the measurements. On the basis of the available ancillary information a set of input parameters was constructed for each case. For input data that were not measured but are needed to frame the model intercomparison, the data set is completed with reasonable estimates based on climatology and atmospheric measurements made elsewhere. Examples include the single-scattering albedo and vertical profile of the aerosols, the choice of the solar spectrum, etc. In this paper the output of the various models is compared on the basis of the treatment of the input data, rather than on the uncertainty in the input data themselves. The effect of uncertainty in the input parameters on the surface UV irradiance has been addressed in several papers [Weihs and Webb, 1997a, b; Schwander et al., 1997; Forster, 1995; Zeng et al., 1994].

In section 2 we specify the input data for the six cases. The various model calculations are evaluated in section 3 against their mean (which we pinpoint as "benchmarks"). In section 4 we present the comparison of the benchmarks with the ob- 
Table 1. Overview of Models, Their Source (Reference and/or Anonymous ftp Address If Available), and Contact Addresses

\begin{tabular}{|c|c|c|c|c|}
\hline Name, Source & $\begin{array}{l}\text { Numerical } \\
\text { Method }\end{array}$ & $\begin{array}{l}\text { Pseudo- } \\
\text { Spherical } \\
\text { Correction }\end{array}$ & Institute & Contact Person + E-Mail \\
\hline BASRTM,1 & discrete ordinates & yes & $\begin{array}{l}\text { British Antarctic Survey (BAS), } \\
\text { Cambridge, England }\end{array}$ & $\begin{array}{l}\text { Brian Gardiner } \\
\text { brian.gardiner@bas.ac.uk }\end{array}$ \\
\hline BOKU-DISORT, 1 & discrete ordinates & no & $\begin{array}{l}\text { Department of Meteorology and Physics, } \\
\text { Universitaet fuer Bodenkultur (BOKU), } \\
\text { Vienna, Austria }\end{array}$ & $\begin{array}{l}\text { Philipp Weihs } \\
\text { weihs@mail.boku.ac.at }\end{array}$ \\
\hline TUV-IASB, 2 & discrete ordinates & yes & $\begin{array}{l}\text { Belgian Institute for Space } \\
\text { Aeronomy (IASB), Brussels }\end{array}$ & $\begin{array}{l}\text { Didier Gillotay } \\
\text { dgill@aero.oma.be }\end{array}$ \\
\hline DAK, 2 & doubling-adding & no & $\begin{array}{l}\text { Royal Netherlands Meteorological } \\
\text { Institute (KNMI), De Bilt }\end{array}$ & $\begin{array}{l}\text { Piet Stammes } \\
\text { stammes@knmi.nl }\end{array}$ \\
\hline TUV-KNMI, 3 & discrete ordinates & no & KNMI, De Bilt, Netherlands & $\begin{array}{l}\text { Michiel van Weele } \\
\text { weelevm@knmi.nl }\end{array}$ \\
\hline LibRadtran, 4 & discrete ordinates & no & $\begin{array}{l}\text { NORUT Information Technology, } \\
\text { Tromso, Norway }\end{array}$ & $\begin{array}{l}\text { Ola Engelsen } \\
\text { Ola.Engelsen@itek.norut.no }\end{array}$ \\
\hline Uvtrans & two- stream & yes & $\begin{array}{l}\text { National Institute of Public Health } \\
\text { and the Environment (RIVM), } \\
\text { Bilthoven, Netherlands }\end{array}$ & $\begin{array}{l}\text { Peter den Outer } \\
\quad \text { Peter.den.Outer@rivm.nl }\end{array}$ \\
\hline DISORT-UI-IMP, 1 & discrete ordinates & yes & $\begin{array}{l}\text { Institute of Medical Physics, } \\
\text { University of Innsbruck (UI-IMP), } \\
\text { Innsbruck, Austria }\end{array}$ & $\begin{array}{l}\text { Mario Blumthaler } \\
\text { mario.blumthaler@uibk.ac.at }\end{array}$ \\
\hline TUV-UG, 3 & discrete ordinates & no & $\begin{array}{l}\text { Institute for Meteorology and } \\
\text { Geophysics, University of Graz, } \\
\text { (IMG-UoG), Graz, Austria }\end{array}$ & $\begin{array}{l}\text { Gabriele Pfister } \\
\text { ggp@bimgs5.kfunigraz.ac.at }\end{array}$ \\
\hline STAR, 5 & matrix operator & yes & $\begin{array}{l}\text { Meteorological Institute, } \\
\text { University of Munich (MI-UM), } \\
\text { Munich, Germany }\end{array}$ & $\begin{array}{l}\text { Ansgar Ruggaber } \\
\text { ruggaber@lrz.uni-muenchen.de }\end{array}$ \\
\hline SOSUSTL & orders of scattering & yes & $\begin{array}{l}\text { Université des Sciences et } \\
\text { Technologies de Lille (USTL), } \\
\text { Villeneuve d'Ascq, France }\end{array}$ & $\begin{array}{l}\text { Jacqueline Lenoble } \\
\text { jacqueline.lenoble@wanadoo.fr }\end{array}$ \\
\hline DISORT-USTL, 1 & discrete ordinates & no & USTL, Villeneuve d'Ascq, France & $\begin{array}{l}\text { Colette Brogniez } \\
\text { Collette.Brogniez@univ-lille1.fr }\end{array}$ \\
\hline
\end{tabular}

Column 3 indicates if pseudospherical corrections are applied in the code. 1, DISORT [Stamnes et al., 1988]: ftp://climate.gsfc.nasa.gov/pub/ wiscombe/Discr_Ord; 2, DAK [De Haan et al., 1987; Stammes et al., 1996]; 3, TUV software-package, including DISORT [Madronich, 1998]: $\mathrm{ftp}$ ://acd.ucar.edu/user/sasha; 4, libRadtran [Kylling, 1998]: ftp://ftp.geofysikk.uio.no/pub/outgoing/arveky/libRadtran.latest.tar.gz; and 5, STAR [Ruggaber et al., 1994]: freely available for research on request.

served spectra. The results are discussed in section 5. Model output and observations presented in this paper can be obtained from the authors. In this way we expect to serve future modelers of spectral surface UV irradiance who would like to validate their model.

\section{Input Specifications}

In this section we discuss the choice of input parameters to the models and implications that follow from these choices. The input parameters are based on independent measurements wherever possible and are summarized in Tables 2, 3, and 4. These tables provide sufficient information for the model calculations to be reproduced for each of the six cases.

Table 2 shows the input parameters that are specific for each case. The location, date, and time are given in columns 2,3 , and 4 and reflect our aim to model realistic situations. The surface pressure, surface albedo, and total ozone are given in columns 6,7 , and 8 . The ozone column and surface pressure are based on measurements at each site. At all three sites the UV surface albedo is typically very low except for snow and ice conditions (case 3 ), and in all cases, its spectral dependence is neglected. The vertical profiles for temperature, ozone, and pressure are climatological and taken from $\mathrm{McClatchey} \mathrm{et} \mathrm{al.}$ [1972]: midlatitude summer profiles are used for all cases except case 3 for which midlatitude winter profiles are taken. The standard ozone profile is scaled to match the measured ozone column at each site.

Table 3 gives sources for the synthesis of various extinction

Table 2. Definition of Six Cases for Which Benchmarks Are Constructed (Except for Aerosol Characteristics)

\begin{tabular}{|c|c|c|c|c|c|c|c|c|}
\hline Case & $\begin{array}{c}\text { Location } \\
\text { (Latitude, Longitude, Elevation) }\end{array}$ & Date & $\begin{array}{c}\text { UT } \\
\text { (Decimal } \\
\text { Hours) }\end{array}$ & $\begin{array}{c}\text { Solar } \\
\text { Zenith } \\
\text { Angle (deg) }\end{array}$ & $\begin{array}{c}\text { Surface } \\
\text { Pressure, } \\
\text { hPa }\end{array}$ & $\begin{array}{l}\text { Surface } \\
\text { Albedo }\end{array}$ & $\begin{array}{c}\text { Total } \\
\text { Ozone, } \\
\text { DU }\end{array}$ & $\begin{array}{l}\text { Vertical } \\
\text { Profiles }\end{array}$ \\
\hline 1 & Ispra $\left(45.82^{\circ} \mathrm{N}, 8.63^{\circ} \mathrm{E}, 214 \mathrm{~m}\right)$ & 25 May 1995 & 0658 & 62.7 & 995 & 0.02 & 318 & $\mathrm{mls}$ \\
\hline 2 & Ispra & 25 May 1995 & 1158 & 25.1 & 995 & 0.02 & 318 & mls \\
\hline 3 & Garmisch-P. $\left(47.48^{\circ} \mathrm{N}, 11.07^{\circ} \mathrm{E}, 730 \mathrm{~m}\right)$ & 5 March 1995 & 0826 & 68.3 & 930 & 0.40 & 399 & $\mathrm{mlw}$ \\
\hline 4 & Garmisch-P. & 28 May 1995 & 1243 & 29.9 & 930 & 0.02 & 327 & mls \\
\hline 5 & Garmisch-P. & 28 May 1995 & 1674 & 69.7 & 930 & 0.02 & 319 & mls \\
\hline 6 & De Bilt $\left(52.10^{\circ} \mathrm{N}, 5.18^{\circ} \mathrm{E}, 17 \mathrm{~m}\right)$ & 25 July 1995 & 1192 & 32.4 & 1019 & 0.02 & 295 & mls \\
\hline
\end{tabular}

Total ozone column, surface pressure, and surface albedo are taken from local observations. The vertical profiles are all climatological. Latitude and longitude are in decimal degrees; UT, universal time; DU, Dobson units; mls, midlatitude summer; mlw, midlatitude winter. 
Table 3. Choices and References for Case-Independent Input Parameters

\begin{tabular}{|c|c|}
\hline \multicolumn{2}{|c|}{ Choice of Input } \\
\hline Spectral range & $280-400 \mathrm{~nm}$ \\
\hline Spectral steps, transmission & $0.05 \mathrm{~nm}$ \\
\hline Spectral steps, surface irradiance & $0.5 \mathrm{~nm}$ \\
\hline Slit function & $\begin{array}{l}\text { triangle with } 1-\mathrm{nm} \text { full width } \\
\text { at half maximum }\end{array}$ \\
\hline Solar spectrum & ATLAS 3 [Van Hoosier, 1996] \\
\hline Ozone cross sections & Paur and Bass [1985] \\
\hline Rayleigh cross sections & Nicolet [1984] \\
\hline $\begin{array}{l}\text { Atmospheric vertical profiles of } \\
\text { pressure, temperature, and ozone }\end{array}$ & McClatchey et al. [1972] \\
\hline Clouds & not included \\
\hline $\begin{array}{l}\text { Absorption by gases other } \\
\text { than ozone }\end{array}$ & not included \\
\hline
\end{tabular}

cross sections used and the solar extraterrestrial irradiance spectrum. The cases do not include cloudy days. Absorption by gases other than ozone is not included in the calculations. The aerosol extinction parameters for each case are given in Table 4. Only the total aerosol optical depth is measured at each site. Considering the aerosol profile, the total aerosol content is split into three regions, which match the approximate extent of the stratosphere, troposphere, and boundary layer. The aerosols are assumed to have a constant number density in each of these regions. For all sites the top of the boundary layer is fixed at $2 \mathrm{~km}$ above sea level, and hence this layer is thinner in the cases in which ground levels above sea level are considered.

The total extinction by aerosols can be determined relatively easily from direct-Sun observations at one or several wavelengths; if it is measured at several wavelengths, it can be fitted to obtain an Angstrom coefficient. Here we miss this information, and we have chosen an Angstrom coefficient of unity; that is, the aerosol extinction is scaled with the inverse of the wavelength. The absorption by aerosols and the phase function are more difficult to measure and must rely on reasonable estimates. Here the aerosol single-scattering albedo and asymmetry parameter have been estimated on the basis of the expected (continental) type of aerosols at each location; the error introduced by the uncertainty on these parameters is small for lowaerosol contents but increases with the total aerosol amount.

In the calculations we use a Henyey-Greenstein phase function [Henyey and Greenstein, 1941]. This function fails to describe the detailed distribution of the radiation scattered once or at low orders of scattering, and it can be a poor approximation for describing the sky radiance in the ozone absorption region, especially near the Sun direction. However, for irradiance we performed computations for a continental aerosol model with the Mie phase function and with the HenyeyGreenstein phase function and found that differences in irradiance are typically limited to $0.2 \%$.

Some care should be taken when considering the medium in which wavelengths are measured. While the ground-level spectrum has wavelengths measured in air, the wavelength scale of the extraterrestrial spectrum and of the ozone absorption spectrum may be quoted in either air at standard temperature and pressure, or in vacuum. Because absorption by ozone is strongly wavelength-dependent, noticeable errors will result if the wrong wavelength is applied, particularly at the shorter UVB wavelengths. Here we will refer to all wavelengths as measured in air under standard temperature and pressure conditions.

The spectral transmissions are calculated in the range from
280 to $400 \mathrm{~nm}$ at steps of $0.05 \mathrm{~nm}$. Note that the calculations should be performed at this high resolution, because of the fine spectral structure of the solar spectrum in this wavelength range and also because of the fine structure of the HartleyHuggins ozone absorption bands. In order to calculate irradiance from transmission we apply the high resolution ATLAS-3 solar spectrum [Van Hoosier, 1996], which has spectral steps of $0.05 \mathrm{~nm}$. The bandwidth of the SUSIM instrument, which was used to measure the ATLAS-3 spectrum, is $\sim 0.15 \mathrm{~nm}$ (full width at half maximum (FWHM)). The modeled surface spectra are convolved with a triangular slit function of 1-nm FWHM to simulate the measurements. The measurements are corrected for wavelength shifts and for the instrument slit function and brought to a 1-nm triangular slit function using the algorithms developed by Slaper et al. [1995].

\section{Model Intercomparison and Benchmarks}

\subsection{Model Intercomparison}

In each model the given input data, describing the atmosphere and various physical values, are translated into the optical parameters that are passed to the routine used to solve the equation of radiative transfer. Typically, a description of the atmosphere is given in terms of temperature and pressure profiles, aerosol optical depths, composition, and vertical distribution. This must be converted to values of extinction coefficient, single-scattering albedo and a scattering phase function. The details of this conversion procedure differ from one model to the next. Some differences between the codes, due to the altitude discretization for example, can be inferred before a radiation calculation is performed. In Table 5 we present for the six cases the mean and standard deviation of the 12 models for the optical thickness due to Rayleigh scattering, due to ozone absorption, and due to the combination of Rayleigh scattering, ozone absorption, and aerosol extinction. Data are given for wavelengths of 310 and $360 \mathrm{~nm}$, which are representative wavelengths for the UV-B and UV-A spectral regions, respectively. Differences in the Rayleigh optical depths are less than $0.5 \%$, which is about the accuracy of Nicolet's empirical formula [Nicolet, 1984]. Some further differences may arise from the use of a different number of vertical layers and different distributions of temperature and (partial) pressure

Table 4. Aerosol Optical Input Parameters for Six Cases

\begin{tabular}{|c|c|c|c|c|c|c|c|c|c|}
\hline \multirow[b]{3}{*}{ Case } & \multicolumn{9}{|c|}{ Aerosol Optical Parameters } \\
\hline & \multicolumn{3}{|c|}{$\begin{array}{l}\text { Boundary Layer } \\
\text { (surface-2 km) }\end{array}$} & \multicolumn{3}{|c|}{$\begin{array}{c}\text { Free } \\
\text { Troposphere } \\
(2-12 \mathrm{~km})\end{array}$} & \multicolumn{3}{|c|}{$\begin{array}{c}\text { Stratosphere } \\
(12-30 \mathrm{~km})\end{array}$} \\
\hline & $\tau(320)$ & $\omega$ & $g$ & $\tau(320)$ & $\omega$ & $g$ & $\tau(320)$ & $\omega$ & $g$ \\
\hline 1 & 1.563 & 0.90 & 0.7 & 0.025 & 1 & 0.6 & 0.003 & 1 & 0.6 \\
\hline 2 & 1.563 & 0.90 & 0.7 & 0.025 & 1 & 0.6 & 0.003 & 1 & 0.6 \\
\hline 3 & 0.016 & 0.95 & 0.7 & 0.025 & 1 & 0.6 & 0.003 & 1 & 0.6 \\
\hline 4 & 0.016 & 0.95 & 0.7 & 0.025 & 1 & 0.6 & 0.003 & 1 & 0.6 \\
\hline 5 & 0.156 & 0.95 & 0.7 & 0.025 & 1 & 0.6 & 0.003 & 1 & 0.6 \\
\hline 6 & 0.250 & 0.95 & 0.7 & 0.025 & 1 & 0.6 & 0.003 & 1 & 0.6 \\
\hline
\end{tabular}

Values are given for $\lambda=320 \mathrm{~nm}$. The total aerosol optical depth $\tau$ is determined from direct Sun observations at each site and assumed to vary spectrally with $1 / \lambda$, while the single-scattering albedo $\omega$ and the asymmetry parameter $g$ are assumed to be spectrally independent. The vertical profile of the aerosol number density is taken to be constant in the boundary layer, the free troposphere, and the stratosphere but varies between these. 
within each atmospheric layer. None of the models shows consistently higher or lower values.

Differences in the ozone optical thickness at $310 \mathrm{~nm}$ are within $0.4 \%$ and probably due to differences in interpolation procedures. All data in Table 5 are given for a wavelength of $310 \mathrm{~nm}$ in air. Values at the vacuum wavelength of $310 \mathrm{~nm}$ will be different from the tabulated values here. Differences in ozone absorption due to temperature effects are small, although differences may exist due to different definitions of atmospheric layers.

The total aerosol optical thickness is prescribed and is therefore the same for all models (Table 4). The variation in the combined optical thickness (Rayleigh scattering plus ozone absorption plus aerosol extinction) is less than $0.4 \%$ for all cases.

The differences discussed for the optical thickness explain a large part of the differences seen in the calculated direct and global spectral transmissions (Figures 1 and 2). The reference in these figures is the mean of the 12 individual calculations. The results for the low Sun (cases 1, 3, and 5) show significantly more variation than the results for the high Sun (cases 2, 4, and 6). Two quite separate groups of models are evident in the UV-B spectral region. This grouping is most clearly visible in the direct transmission and for low Sun (Figure 1, cases 1, 3, and 5). The calculations with highest direct transmission represent models that use corrections for pseudospherical geometry (PS corrections) in their calculations; the other group represents codes without PS corrections. Pseudospherical corrections imply that the sphericity of the Earth's atmosphere is taken into account in the treatment of the direct radiation, i.e., for the directly transmitted radiation from the Sun and also for the direct radiation contributing to the scattering source function. In Figure 1, one of the codes uses the two-stream approximation and therefore shows significantly higher global transmission for UV-B wavelengths [Forster and Shine, 1995].

For the high-Sun cases the calculated direct and global spectral transmissions are within $5 \%$ of the mean above $300 \mathrm{~nm}$ and within $10 \%$ of the mean above $295 \mathrm{~nm}$. For the low-Sun cases the direct and global spectral transmissions are also within $5 \%$ in the UV-A (>320 $\mathrm{nm})$, but differences are larger than $20 \%$ at $300 \mathrm{~nm}$ due to the differences between models with and without PS corrections. The variations within these two groups of models are within $10 \%$. The absolute values for the low-Sun cases are very small at these wavelengths.

Table 5. Spectral Optical Depths at 310 and $360 \mathrm{~nm}$ As Derived in Various Models From Chosen Input Parameters

\begin{tabular}{lcccccccc}
\hline & \multicolumn{2}{c}{ Rayleigh } & & \multicolumn{2}{c}{ Ozone } & & \multicolumn{2}{c}{ Total } \\
\cline { 2 - 3 } \cline { 7 - 8 } Case & $310 \mathrm{~nm}$ & $360 \mathrm{~nm}$ & & $310 \mathrm{~nm}$ & $360 \mathrm{~nm}$ & & $310 \mathrm{~nm}$ & $360 \mathrm{~nm}$ \\
\hline \multirow{2}{*}{$1+2$} & 1.035 & 0.548 & 0.740 & 0.0 & & 3.417 & 1.961 \\
& $(0.4 \%)$ & $(0.3 \%)$ & & $(0.4 \%)$ & & & $(0.1 \%)$ & $(0.1 \%)$ \\
3 & 0.968 & 0.512 & 0.910 & 0.0 & & 1.922 & 0.551 \\
& $(0.3 \%)$ & $(0.3 \%)$ & & $(0.2 \%)$ & & & $(0.2 \%)$ & $(0.3 \%)$ \\
4 & 0.970 & 0.513 & 0.761 & 0.0 & & 1.776 & 0.552 \\
& $(0.4 \%)$ & $(0.4 \%)$ & $(0.4 \%)$ & & & $(0.2 \%)$ & $(0.4 \%)$ \\
5 & 0.970 & 0.513 & 0.743 & 0.0 & & 1.902 & 0.677 \\
& $(0.4 \%)$ & $(0.4 \%)$ & $(0.4 \%)$ & & & $(0.2 \%)$ & $(0.3 \%)$ \\
6 & 1.059 & 0.561 & 0.687 & 0.0 & & 2.033 & 0.808 \\
& $(0.5 \%)$ & $(0.5 \%)$ & $(0.4 \%)$ & & & $(0.3 \%)$ & $(0.3 \%)$ \\
\hline
\end{tabular}

The given values are averages of the 12 models for Rayleigh scattering, ozone absorption, and total extinction. Standard deviations in parentheses reflect the variations due to different treatment of the input data.
Direct Transmission
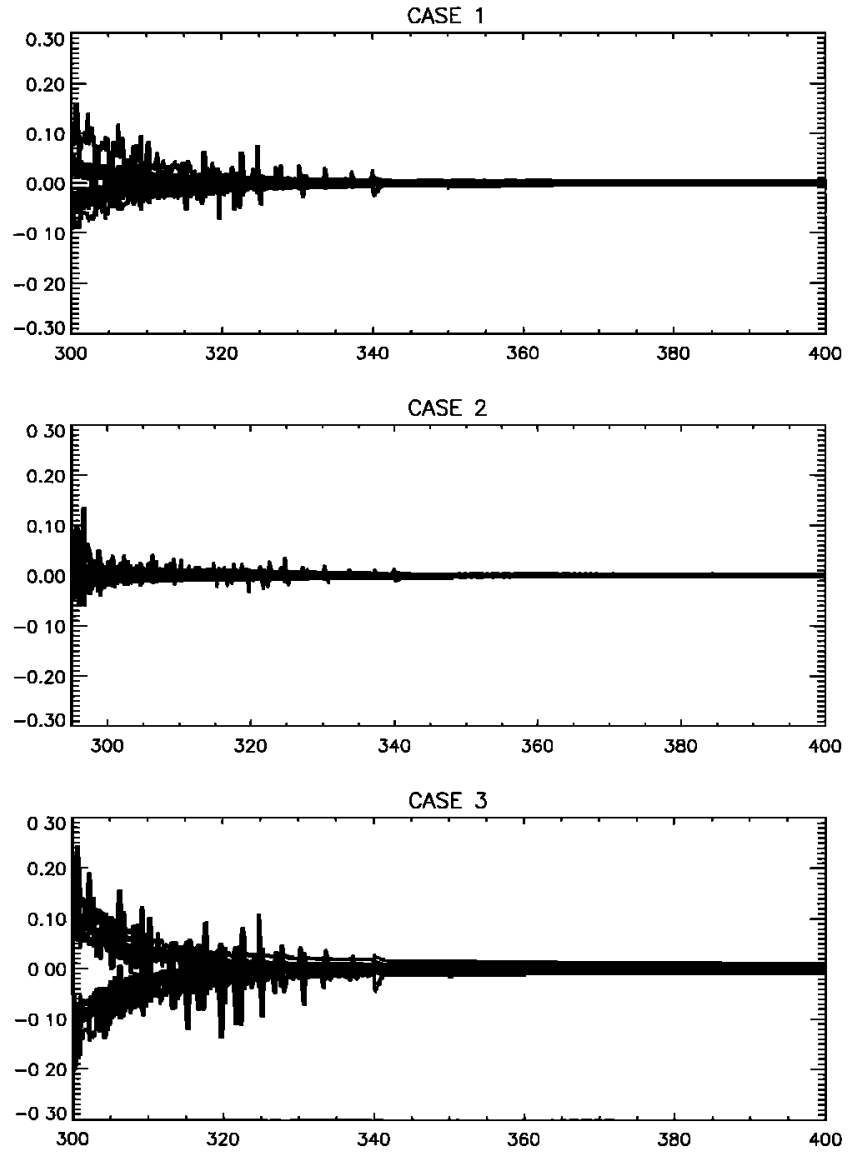

Figure 1. Twelve model calculations of the spectral direct transmission, calculated every $0.05 \mathrm{~nm}$, relative to their mean, for each of the six cases. The ordinate is (model minus mean)/ mean.

The transmission calculations for the orders-of-scattering code (SOSUSTL) were run with $0.5-\mathrm{nm}$ resolution up to 345 $\mathrm{nm}$ and with $5-\mathrm{nm}$ resolution above (instead of $0.05 \mathrm{~nm}$ over the whole domain). Intermediate calculations for this code are obtained by linear interpolation of the transmission results. Most of the "spikes" in Figures 1 and 2 result from the interpolation procedure for this code. Some of the spikes can be ascribed to differences in the wavelength interpolations of the Paur and Bass ozone cross sections.

The calculated direct and global spectral surface irradiances for the six cases are shown in Figures 3 and 4. The spectral irradiances are calculated from the product of the transmission data with 0.05-nm steps and the ATLAS-3 high-resolution solar spectrum. This product is corrected for the Sun-Earth distance and afterward convolved with a triangular slit function with 1-nm FWHM. The spectral irradiance is reduced to wavelength steps of $0.5 \mathrm{~nm}$. The main difference with the transmission calculations is therefore that due to the convolution some of the fine spectral structure is smoothed out. In Figure 3 for the direct irradiance the groups of models with and without pseudospherical corrections are again clearly distinguished. Figure 4 shows that most variation in global irradiance is found for UV-B wavelengths in combination with low Sun. The twostream calculation clearly overestimates the global irradiance in these cases. Variations in global irradiance are comparable 
Direct Transmission
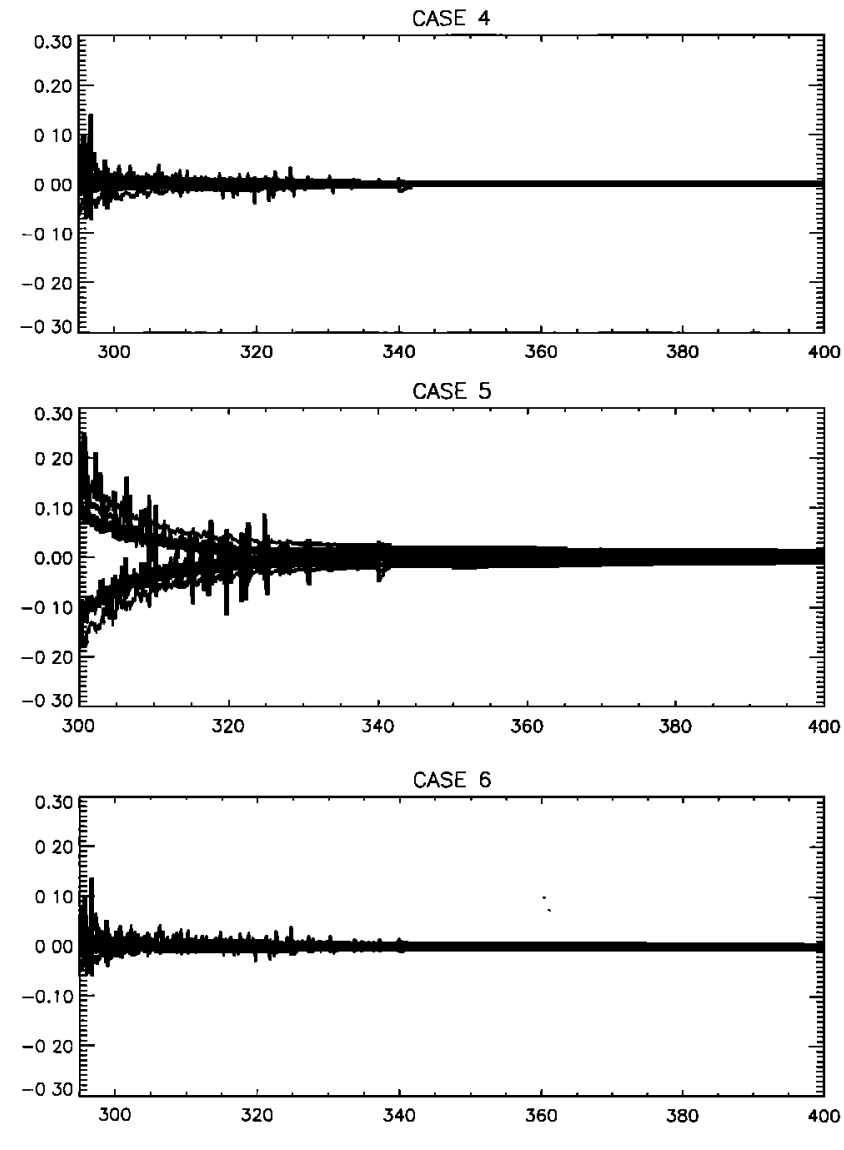

Figure 1. (continued)

with the variations in global transmission but exclude the spikes that are seen in Figure 2.

\subsection{Benchmarks}

In Tables 6 and 7 we give for each case the benchmark values at 310 and $360 \mathrm{~nm}$ for the direct and global transmission and for the direct and global surface irradiance. In Table 7 we also give the erythemally weighted irradiance. The UV index, defined by WMO (World Meteorological Organization) together with WHO (World Health Organization) for the information of population, measures the strength of the health effective portion of UV irradiance and relates to the erythemal action spectrum due to McKinlay and Diffey [1987]. The UV index is defined as the erythemally weighted irradiance (W $\mathrm{m}^{-2}$ ) from 100 to $400 \mathrm{~nm}$ divided by 25 [WMO, 1994].

For the high-Sun cases 2, 4, and 6 the benchmarks for direct transmission and direct irradiance are obtained by taking the average over the 12 model calculations. The benchmarks for global transmission and global irradiance are obtained by taking the average over 11 model calculations. Here the results of the two-stream method are left out because in all cases the global transmission and global irradiance calculated with the two-stream code are significantly higher in the UV-B spectral region (up to about $20 \%$ for the global irradiance in cases 3 and 5).

For the benchmarks of the low-Sun cases 1, 3, and 5, a distinction is made between two groups of results: one with pseudospherical (PS) corrections and the other with planeparallel geometry, without PS corrections. For the direct trans- mission and direct irradiance the benchmarks with PS correction and the benchmarks without PS correction are both based on the results of six models. The benchmarks with PS correction for global transmission and global irradiance are based on five models (again leaving out the two-stream results).

For each of the benchmark values a standard deviation has been calculated. These standard deviations give the uncertainty of the benchmarks with respect to one specific code. For all the benchmarks that are given in Tables 6 and 7 the standard deviations are smaller than $2 \%$. For the high-Sun cases the standard deviations in the benchmarks of the global irradiance are smaller than $2 \%$ down to $295 \mathrm{~nm}$. For the low-Sun cases and at wavelengths shorter than $310 \mathrm{~nm}$ the standard deviations are somewhat larger. For example, the standard deviation in the benchmark of the global irradiance at $300 \mathrm{~nm}$ for the low Sun cases is $5 \%$. In these cases the absolute value of the global irradiance is less than $0.1 \mathrm{~mW} \mathrm{~m}^{-2} \mathrm{~nm}^{-1}$.

\section{Comparison of Benchmarks With Measured Spectra}

The benchmarks for global irradiance that include corrections for pseudospherical geometry are compared with the observed spectra for the six cases considered. Figure 5 shows the relative difference between the benchmarks and the measured spectral irradiances (model-measurement)/measure-

Global Transmission
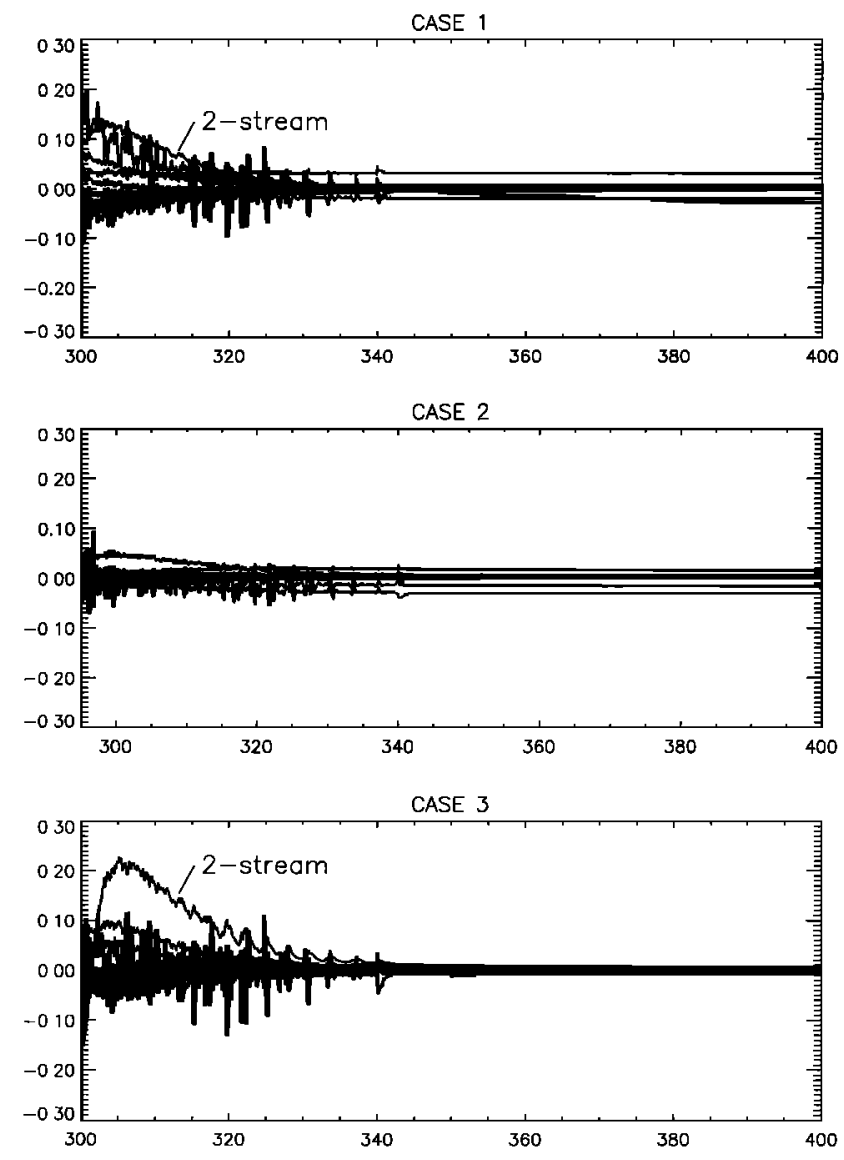

Figure 2. Same as Figure 1 but for the spectral global transmission and relative to the mean of 11 (excluding the twostream calculation). Two-stream model results are indicated for the cases with low Sun (cases 1, 3, and 5). 
ment. The standard deviations of the benchmarks are indicated in the figures and show that in all cases the differences between the model calculations are much smaller than the differences that exist between the models and the observations. The standard deviations are largest for short wavelengths and large solar zenith angles. The difficulty in accurately modeling cases of low solar elevation is clear.

Best agreement with the observations is found for the highSun cases 2, 4, and 6. Here differences between the benchmarks and the measurements are less than $10 \%$ for wavelengths longer than $297 \mathrm{~nm}$. In case 6 , benchmark and measurements differ by more than $10 \%$ for wavelengths between 295 and $304 \mathrm{~nm}$. For the low-Sun cases 1, 3, and 5 the differences are less than $10 \%$ for case 1 and less than $20 \%$ for case 5, while the largest differences (more than 20\%) occur at short wavelengths for case 3 . Because of the low solar elevation the absolute incident irradiances are very small at these wavelengths.

Differences between the benchmarks and the observations can be explained by the uncertainties in the extraterrestrial spectrum, measurement errors, and the uncertainty in the input parameters for the benchmark calculations. The relative importance of these factors is discussed in the next section. In the remainder of this section we discuss shortly, for each case, how much of the differences between the benchmarks and the observed spectra can be explained by uncertainty in the input parameters, and we suggest which of the chosen input param-

Global Transmission

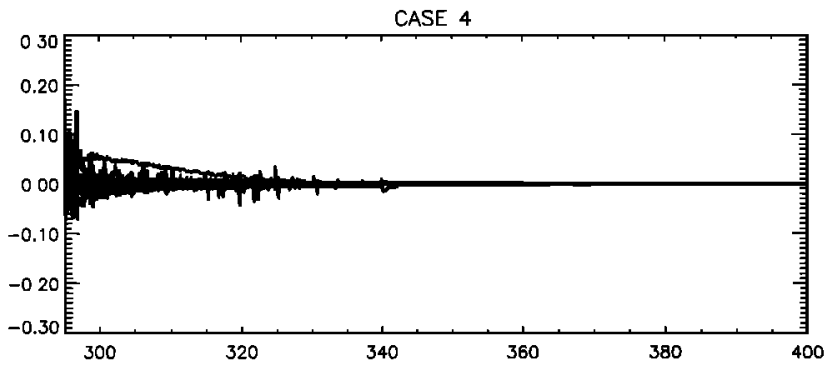

CASE 5

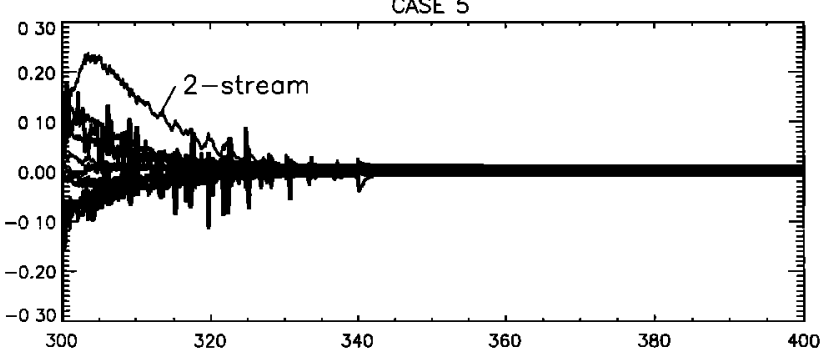

CASE 6

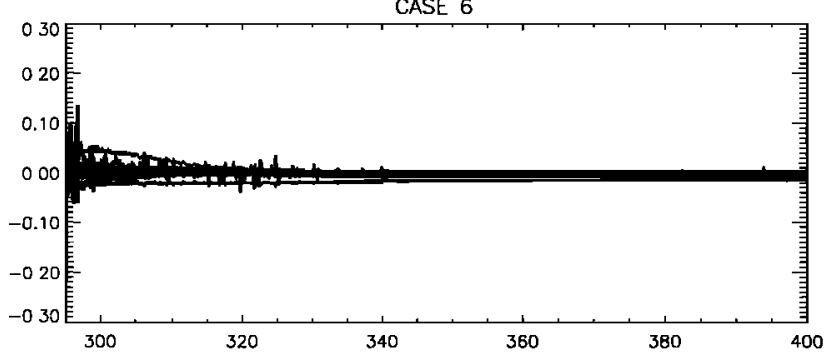

Figure 2. (continued)
Direct Irradiance
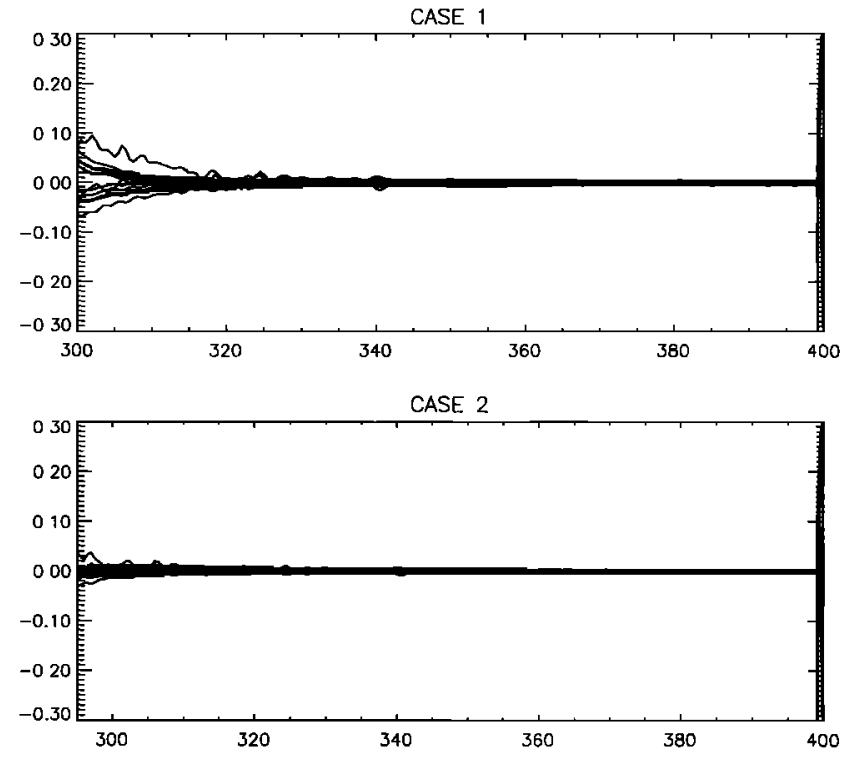

CASE 3

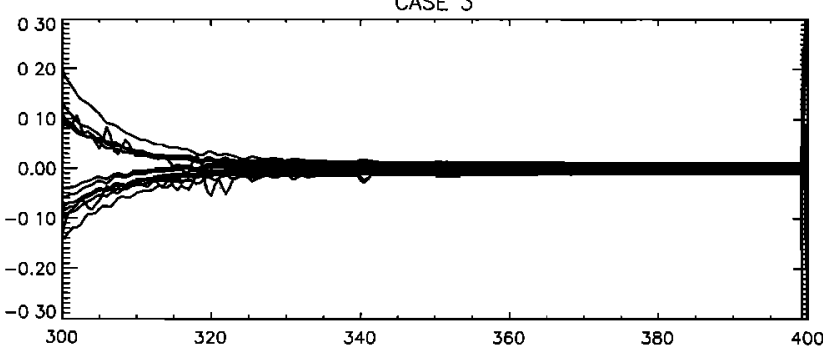

Figure 3. Twelve model calculations of the spectral direct irradiance, relative to their mean, for each of the six cases. The spectral irradiance is calculated every $0.5 \mathrm{~nm}$ with $1-\mathrm{nm}$ resolution. The ordinate is (model minus mean)/mean.

eters may be responsible. We make use of the results of earlier studies on the effect of uncertainty in input parameters on the UV surface irradiance [Weihs and Webb, 1997a, b; Schwander et al., 1997; Forster, 1995; Zeng et al., 1994].

For case 1 in Ispra, with low Sun, the model calculations are about $10 \%$ low relative to the measurements in the UV-A without significant spectral dependence. The larger differences at shorter wavelengths are due to small differences in the ozone column. Because of the large aerosol optical depth the lack of information on the composition and size distribution of the aerosols is important in this case. The uncertainty in the single-scattering albedo and the asymmetry parameter of the aerosols is large. Weihs and Webb [1997a] show for a comparable case study that $7 \%$ uncertainty in the single-scattering albedo results in about $8 \%$ uncertainty in the spectral irradiance at both UV-A and UV-B wavelengths.

For case 2 in Ispra, with high Sun, the heavy aerosol load at Ispra is modeled more successfully. A slight tendency is observed from small positive differences at short wavelengths to small negative differences in the UV-A, which is attributed to the uncertainty in the ozone column, and to the singlescattering albedo and the asymmetry parameter of the aerosols. For the low-Sun case with snow in Garmisch-Partenkirchen (case 3) the model calculations are close $(<5 \%)$ around $360 \mathrm{~nm}$ but about $10 \%$ high around $330 \mathrm{~nm}$ and even more at $300 \mathrm{~nm}$. Differences can be ascribed to the assump- 
Direct Irradiance

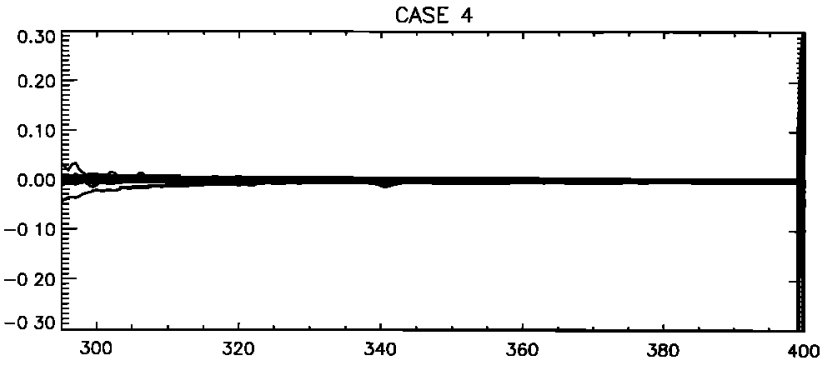

CASE 5

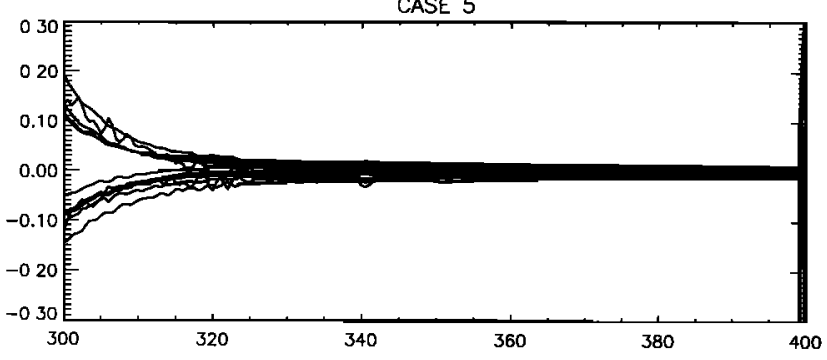

CASE 6

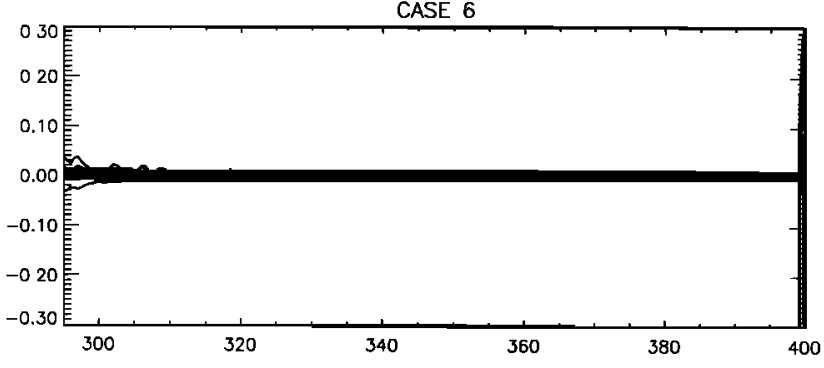

Figure 3. (continued)

tions on the low-aerosol load and the aerosol type, and on the assumed spectrally independent surface albedo. Long-term comparisons between model calculations and observations show a systematic difference at the Fraunhofer Institute in Garmisch-Partenkirchen [Mayer et al., 1997]. This systematic difference is between $-11 \%$ and $+2 \%$ and is ascribed to uncertainties in both the model calculations and the measurements. The complex topography of the site in GarmischPartenkirchen, which cannot be included in the model calculations, may also be partly responsible for the differences seen.

For the clean atmosphere and high-Sun spectrum in Garmisch-Partenkirchen (case 4) the differences are within $10 \%$, again with a slight tendency for higher modeled irradiances. For the low-Sun case on the same day (case 5) the model calculations are more than $15 \%$ higher in the UV-A but lower around $304 \mathrm{~nm}$. Apart from the change in solar zenith angle, the main difference between cases 5 and 4 is the aerosol optical thickness, which increased significantly during the day. Therefore the increased difference possibly reflects the increased importance of the uncertainty in the aerosol characteristics. All cases in Garmisch-Partenkirchen (cases 3, 4, and 5) show the systematic difference between observations and model calculations, as discussed by Mayer et al. [1997].

The case in De Bilt at sea level (case 6) with high Sun and moderate aerosol load shows benchmark calculations that differ by less than about $10 \%$ from the measurements. The uncertainty in the aerosol single-scattering albedo can explain the differences in the UV-A spectral region. The larger differences in the UV-B spectral region can be ascribed to the uncertainty in the ozone column (a few percent) and to the uncertainty in the ozone profile. Overall, most of the uncertainty in the input parameters for the different cases is attributable to the uncertainty in the aerosol type and size, i.e., the single-scattering albedo and asymmetry parameter of the aerosols. The uncertainties in the extraterrestrial spectrum are also important. The surface albedo contributes significantly to the uncertainty in case 3. Uncertainties in aerosol optical depth, ozone column, and ozone profile are generally small. In all cases the observed deviations between the model results and the measurements lie within the combined uncertainty of model and measurement.

\section{Discussion}

Twelve radiative transfer models have been compared for six different situations, using common input parameters in each case. The cases considered are based on situations for which measurements of spectral irradiance also exist. After separating the calculations made with and without pseudospherical corrections and eliminating the two-stream calculation, the computed spectral global irradiances agree to within $2 \%$ for wavelengths longer than $310 \mathrm{~nm}$. At $300 \mathrm{~nm}$ they agree to within 5\% for the cases with large solar zenith angles and within $2 \%$ for the cases with small solar zenith angles. The

Global Irradiance
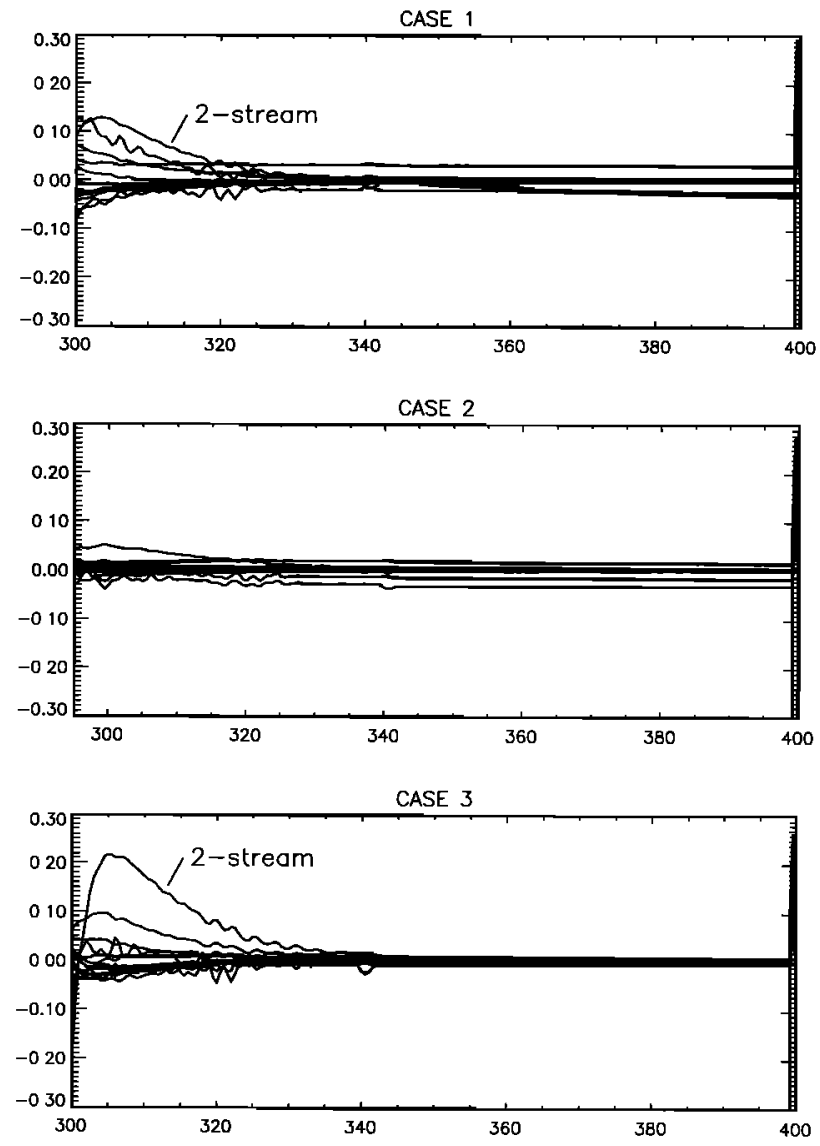

Figure 4. Same as Figure 3 for the spectral global irradiance but relative to the mean of 11 (excluding the two-stream approximation). Two-stream model results are indicated for the cases with low Sun (cases 1, 3, and 5). 
Global Irradiance
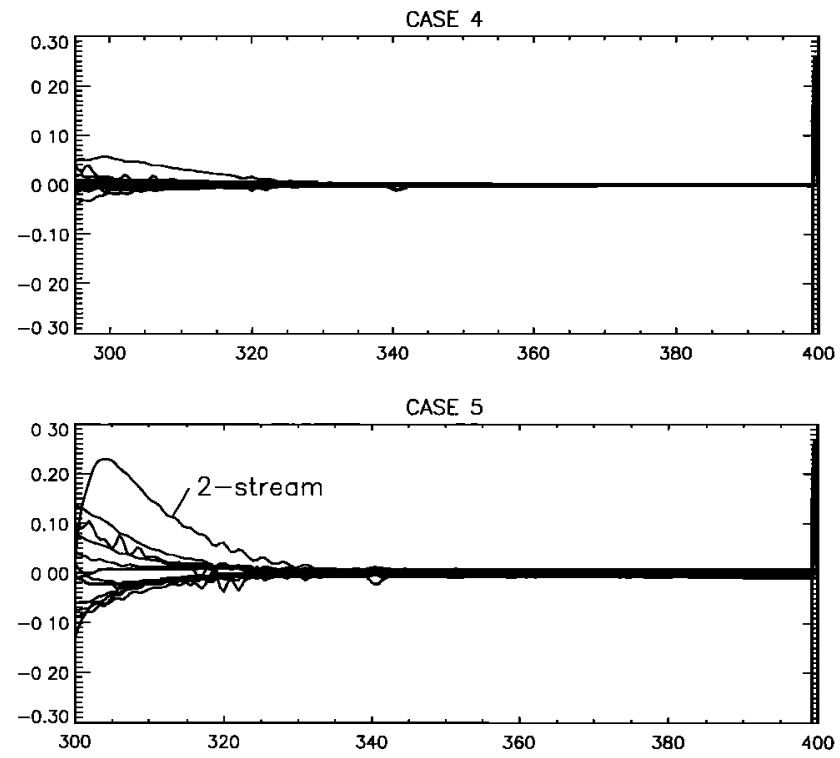

CASE 6

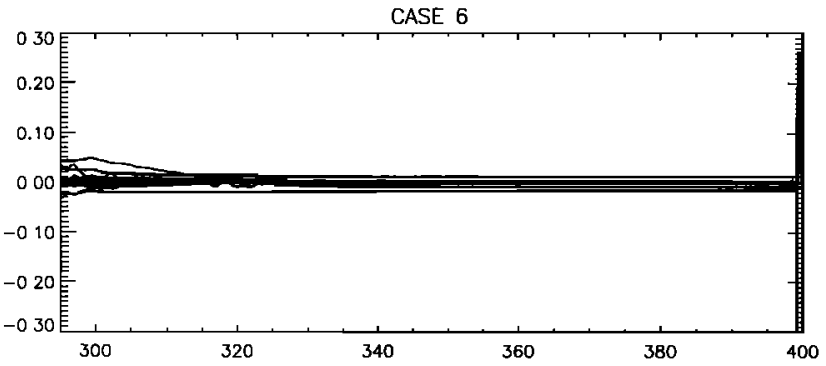

Figure 4. (continued)

mean of the calculations for each case, with its dispersion, constitutes a benchmark for testing future models. These benchmark spectra can be obtained directly from the authors or via http://www.knmi.nl/ weelevm/benchmarks.html or the SUVDAMA home page at http://www.ozone(mi.fi/SUDAMA. The presence of small errors in the individual calculations used to construct the benchmarks can never be excluded. However, none of the model results deviate systematically from the others, except for the two-stream method, and that was expected. The two-stream calculations are therefore not incorporated in the benchmarks. Figure 4 shows that the two-stream method is very accurate at UV-A wavelengths for clear-sky cases, while at
UV-B wavelengths, deviations are small for the cases with small solar zenith angle.

Two groups of model calculations are distinguished: one group using corrections for pseudospherical geometry and one group without these corrections. The differences between these groups are largest at UV-B wavelengths and low Sun. The clear distinction between models with and without pseudospherical corrections shows the importance of these corrections for surface UV-B irradiance calculations at low solar elevations. Because of the combination of long path lengths and strong absorption the interpolation and discretization aspects become critical in these cases.

When examining calculations of atmospheric transmission, we find that interpolation of input parameters, cross-section data or the calculated transmission results can lead to significant (up to $10 \%$ ) small-scale variations in the global transmission in the UV-B spectral region. Differences are significantly smaller for the spectral irradiance than for the transmission, because these spectra have been convolved with a 1-nm FWHM slit function.

The benchmarks for spectral global irradiance with pseudospherical corrections are compared with measurements. Differences between the benchmarks and the measured spectra can approach $20 \%$ at the shortest wavelengths in some of the cases. Such differences can be expected given the uncertainty in the input parameters, particularly for aerosol optical properties and surface albedo. Several of the important input parameters for the six cases are estimated and not directly measured. The size of the differences in the cases presented here are comparable to those shown in earlier clear-sky comparisons [Wang and Lenoble, 1994; Zeng et al., 1994; Forster et al., 1995; Mayer et al., 1997].

The most uncertain input parameters are the aerosol characteristics, such as the spectral variation of extinction, phase function, and single-scattering albedo; the last parameter characterizes the aerosol absorption and has a very important impact on the computed irradiance. When the aerosol loading is small, the uncertainty in the aerosol properties is of less importance and the differences between models and measurements are reduced. For details of the size and the spectral signature of uncertainties in specific input parameters the reader is referred to papers by Zeng et al. [1994], Weihs and Webb [1997a], and Schwander et al. [1997]. Further, neglecting polarization effects will also contribute to the uncertainty in irradiance calculations. Another source of uncertainty in the

Table 6. Benchmarks for Direct and Global Transmission at 310 and $360 \mathrm{~nm}$

\begin{tabular}{|c|c|c|c|c|c|c|c|c|}
\hline \multirow[b]{3}{*}{ Case } & \multicolumn{4}{|c|}{ Direct Transmission } & \multicolumn{4}{|c|}{ Global Transmission } \\
\hline & \multicolumn{2}{|c|}{$310 \mathrm{~nm}$} & \multicolumn{2}{|c|}{$360 \mathrm{~nm}$} & \multicolumn{2}{|c|}{$310 \mathrm{~nm}$} & \multicolumn{2}{|c|}{$360 \mathrm{~nm}$} \\
\hline & $+\mathbf{P S}$ & $-\mathrm{PS}$ & + PS & $-\mathbf{P S}$ & + PS & $-\mathbf{P S}$ & $+\mathbf{P S}$ & $-\mathbf{P S}$ \\
\hline 1 & $5.9810^{-4}$ & $5.8410^{-4}$ & 0.0139 & 0.0139 & 0.0229 & 0.0221 & 0.162 & 0.161 \\
\hline 2 & 0.0230 & 0.0230 & 0.115 & 0.115 & 0.148 & 0.148 & 0.478 & 0.478 \\
\hline 3 & $5.9110^{-3}$ & $5.5210^{-3}$ & 0.227 & 0.225 & 0.0166 & 0.0159 & 0.248 & 0.246 \\
\hline 4 & 0.129 & 0.129 & 0.529 & 0.529 & 0.211 & 0.211 & 0.666 & 0.666 \\
\hline 5 & $4.5010^{-3}$ & $4.1610^{-3}$ & 0.144 & 0.142 & 0.0175 & 0.0166 & 0.190 & 0.189 \\
\hline 6 & 0.0900 & 0.0900 & 0.384 & 0.384 & 0.198 & 0.198 & 0.604 & 0.604 \\
\hline
\end{tabular}

For the low-Sun cases 1,3 , and 5 , two values are given: in the left-hand columns the average of the models run with correction for pseudospherical geometry (+PS), and in the right-hand columns the average of the models run without PS-geometry correction (-PS). Standard deviations for the given values are less than $2 \%$. 
Table 7. Benchmarks for Direct and Global Irradiance at 310 and $360 \mathrm{~nm}$ and for Erythemal Irradiance

\begin{tabular}{|c|c|c|c|c|c|c|c|c|c|c|}
\hline \multirow[b]{3}{*}{ Case } & \multicolumn{4}{|c|}{ Direct Irradiance, $\mathrm{mW} \mathrm{m}^{-2} \mathrm{~nm}^{-1}$} & \multicolumn{4}{|c|}{ Global Irradiance, $\mathrm{mW} \mathrm{m}^{-2} \mathrm{~nm}^{-1}$} & \multirow{2}{*}{\multicolumn{2}{|c|}{$\begin{array}{l}\text { Erythemal } \\
\text { Irradiance, } \\
\mathrm{mW} \mathrm{m}^{-2}\end{array}$}} \\
\hline & \multicolumn{2}{|c|}{$310 \mathrm{~nm}$} & \multicolumn{2}{|c|}{$360 \mathrm{~nm}$} & \multicolumn{2}{|c|}{$310 \mathrm{~nm}$} & \multicolumn{2}{|c|}{$360 \mathrm{~nm}$} & & \\
\hline & + PS & $-\mathbf{P S}$ & $+\mathrm{PS}$ & $-\mathrm{PS}$ & $+\mathrm{PS}$ & $-\mathbf{P S}$ & $+\mathrm{PS}$ & $-\mathrm{PS}$ & $+\mathrm{PS}$ & $-\mathrm{PS}$ \\
\hline 1 & 0.144 & 0.142 & 6.91 & 6.90 & 12.1 & 11.7 & 175 & 174 & 22.7 & 22.1 \\
\hline 2 & 11.0 & 11.0 & 112 & 112 & 78.2 & 78.2 & 517 & 517 & 140 & 140 \\
\hline 3 & 1.19 & 1.12 & 94.9 & 93.9 & 9.10 & 8.72 & 280 & 278 & 24.9 & 24.4 \\
\hline 4 & 59.0 & 59.0 & 495 & 495 & 111 & 111 & 720 & 720 & 193 & 193 \\
\hline 5 & 0.818 & 0.764 & 53.9 & 53.2 & 9.20 & 8.77 & 205 & 204 & 20.9 & 20.3 \\
\hline 6 & 39.9 & 39.9 & 349 & 349 & 104 & 104 & 651 & 651 & 186 & 186 \\
\hline
\end{tabular}

Otherwise, the same as Table 6 . Standard deviations for the given values are less than $2 \%$. Note that the here given values, as opposed to the transmissions in Table 6, include the correction for the Earth-Sun distance.

comparison between model calculations and measurements is the uncertainty in the solar spectrum that is applied in the model calculations. The uncertainty in the absolute irradiances of the ATLAS 3 is $3 \%$. The wavelength scale is accurate to 0.05 $\mathrm{nm}$ (M. Van Hoosier, personal communication, 1996). Apart from uncertainty in input parameters for the model calculations, measurement errors can be the cause of the differences between models and measurements. The most important mea-
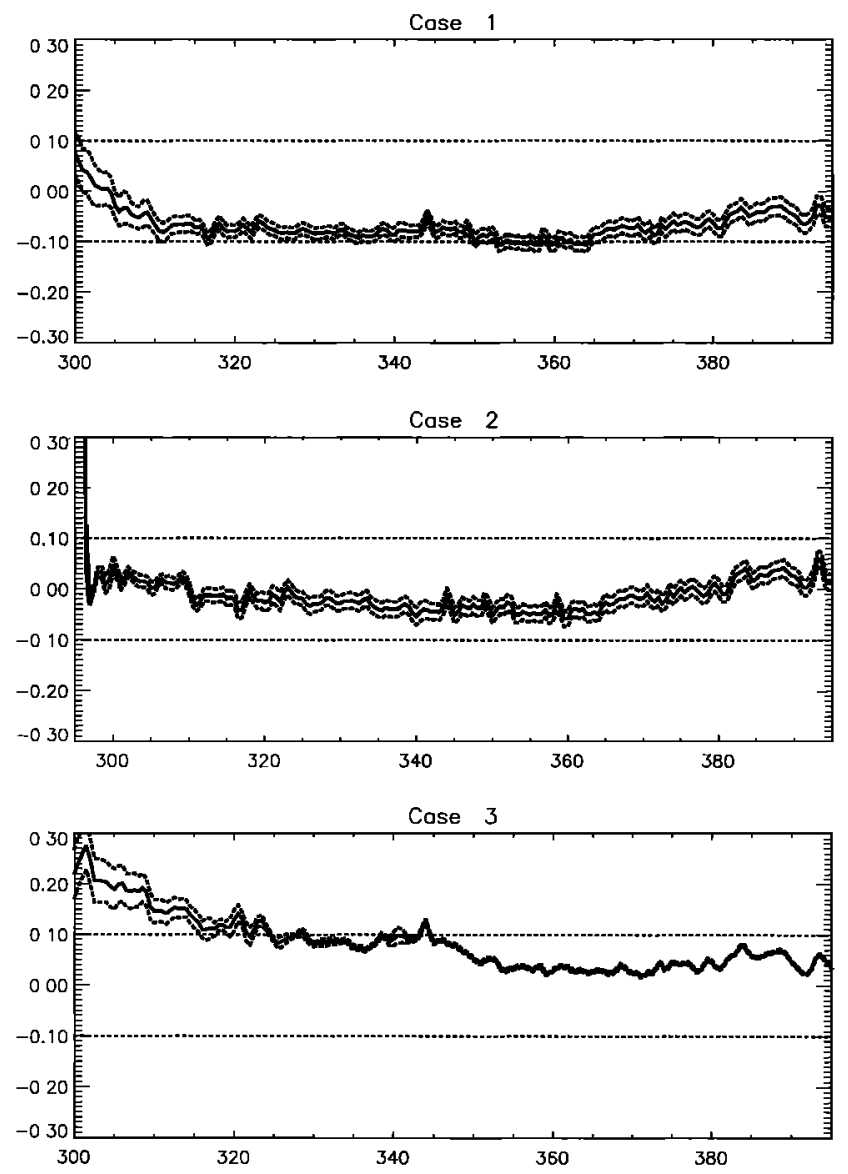

Figure 5. Comparison of the benchmarks for spectral global irradiance which include pseudospherical correction, with the measured spectral global irradiance, for each of the six cases. The ordinate is (model minus measurement)/measurement. Dotted lines indicate variations due to different models. surement errors include errors in absolute calibration and spectral alignment. Given the convolution of the measurements to 1-nm resolution, it can be assumed that the errors due to wavelength shifts are small in the UV-A spectral region. However, significant systematic errors due to wavelength shifts may occur in the UV-B spectral region. Uncertainties in the absolute calibrations are difficult to estimate. Cases 1 and 2 are reference spectra from the instrument intercomparison at Ispra. The other spectra are measured with the Bentham double monochromator of the Fraunhofer Institute in GarmischPartenkirchen (cases 3, 4, and 5) and the Brewer 100 of the
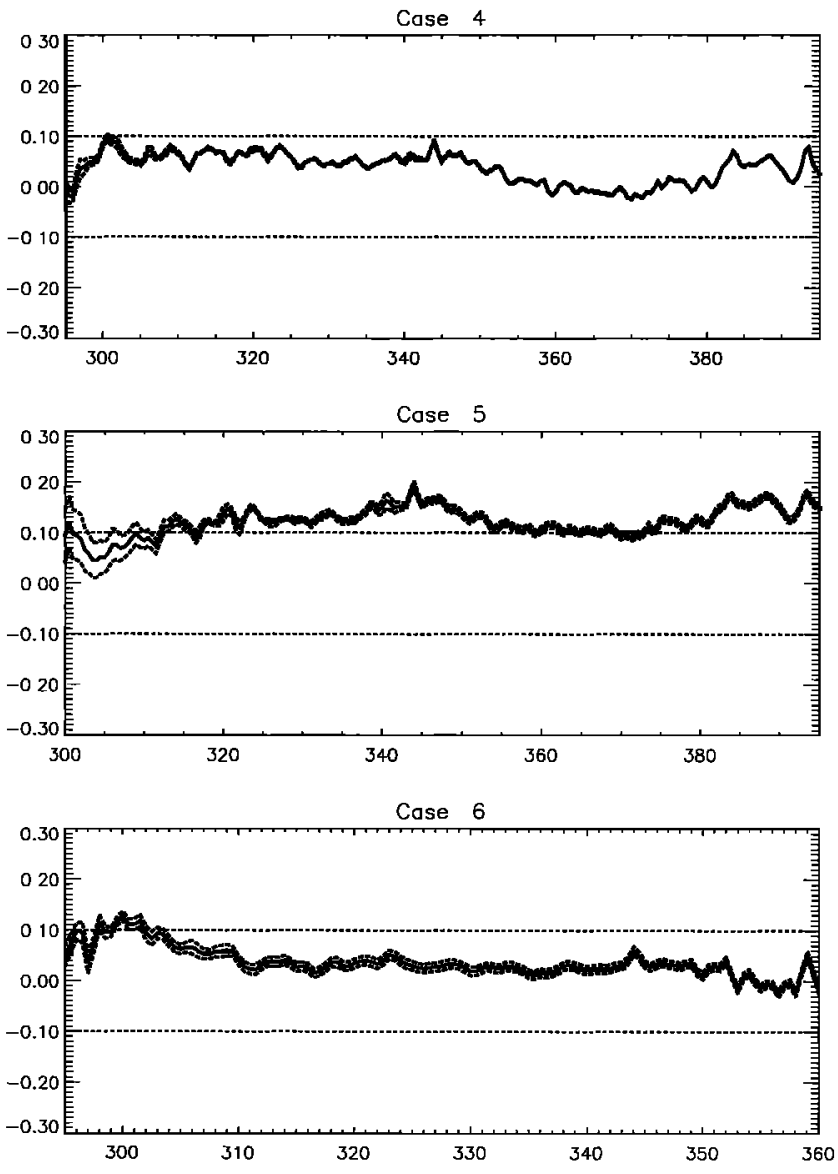

Figure 5. (continued) 
Royal Netherlands Meteorological Institute (case 6). Both instruments regularly participate in instrument intercomparisons. On the basis of the results of the intercomparisons it is estimated that the uncertainty in absolute irradiances in the six cases is within a few percent. Cosine corrections have been applied to the measured spectra in Garmisch-Partenkirchen but not to the Ispra reference spectra and not to the De Bilt spectrum. This may explain part of the differences for case 1 with a solar zenith angle of about $60^{\circ}$.

The main achievement of this work is to have helped the modelers to improve their own models and to provide good quality benchmarks to the scientific community. All participants in this project benefited greatly from the intercomparison. The exercise helped in the identification of minor errors and poor approximations in the numerical models. The 12 models that took part can now be used with confidence and can be expected to return reliable results under a wide range of atmospheric conditions.

It is clear that the greatest difficulty in the modeling of radiative transfer lies in the provision of the atmospheric parameters required as input to the models, particularly the optical characteristics of aerosols and surface albedo. A future task is to improve the agreement between models and measurements with extended and accurate ancillary data obtained at the measurement sites. The large amount of spectral, broadband, and ancillary data collected in the SUVDAMA database will enable further progress to be made, with comparisons for many cases allowing a statistical analysis of model and measurement deviations.

\section{References}

Benassi, M., R. D. M. Garcia, A. H. Karp, and C. E. Siewert, A high-order spherical harmonics solution to the standard problem in radiative transfer, Astrophys. J., 280, 853-864, 1984.

De Haan, J. F., P. B. Bosma, and J. W. Hovenier, The adding method for multiple scattering computations of polarized light, Astron. Astrophys., 183, 371-391, 1987.

Forster, P. M. F., Modelling ultraviolet radiation at the earth's surface, part I, The sensitivity of ultraviolet irradiances to atmospheric changes, J. Appl. Meteorol., 34, 2412-2425, 1995.

Forster, P. M. F., and K. P. Shine, A comparison of two radiation schemes for calculating ultraviolet radiation, Q.J. R. Meteorol. Soc., 121, 1113-1131, 1995.

Garcia, R., and C. Siewert, Benchmark results in radiative transfer, Rad. Trans. Theor. Stat. Phys., 14, 437-484, 1985.

Gardiner, B. G., and P. J. Kirsch, Intercomparison of ultraviolet spectroradiometers, in Advances in Solar Ultraviolet Spectroradiometry edited by A. R. Webb, Air Pollut. Res. Rep., 63, 67-151, 1997.

Henyey, L. G., and J. L. Greenstein, Diffuse radiation in the galaxy, Astrophys. J., 93, 70-83, 1941.

Koepke, P., et al., Comparison of models used for UV index calculations, Photochem. Photobiol., 67, 657-662, 1998.

Kylling, A., The LibRadtran software package, http://www.uio.no/ arveky/libRadtran.html, 1998.

Lenoble, J. (Ed.), Radiative Transfer in Scattering and Absorbing Atmospheres: Standard Computational Procedures, A. Deepak, Hampton, Va., 1985.

Madronich, S., The TUV software package, ftp://acd.ucar.edu/user/ sasha, 1998.

Mayer, B., G. Seckmeyer, and A. Kylling, Systematic long-term comparison of spectral UV measurements and UVSPEC modeling results, J. Geophys. Res., 102, 8755-8767, 1997.

McClatchey, R. A., R. W. Fenn, J. E. A. Selby, F. E. Volz, and J. S. Garing, Optical properties of the atmosphere, Rep. AFCRL-720497, Air Force Cambridge Res. Lab., Cambridge, Mass., 1972.

McKinlay, A. F., and B. L. Diffey, A reference action spectrum for ultraviolet induced erythema in human skin, $C I E J ., 6,17-22,1987$.

Nicolet, M., On the molecular scattering in the terrestrial atmosphere: An empirical formula for its calculations in the homosphere, Planet. Space Sci., 32, 1467-1468, 1984.
Paur, R. J., and A. M. Bass, The ultraviolet cross sections of ozone, II, Results and temperature dependence, in Atmospheric Ozone, Proceedings of the Quadrennial Ozone Symposium, edited by C. S. Zerefos and A. Ghazi, pp. 611-616, D. Reidel, Norwell, Mass., 1985.

Pomraning, G. C., On the Henyey-Greenstein approximation to scattering phase functions, J. Quant. Spectrosc. Radiat. Transfer, 39 $109-113,1988$.

Ruggaber, A., R. Dlugi, and T. Nakajima, Modelling radiation quantities and photolysis frequencies in the troposphere, J. Atmos. Chem., 18, 171-210, 1994.

Schwander, H., P. Koepke, and A. Ruggaber, Uncertainties in modelled UV irradiances due to limited accuracy and availability of input data, J. Geophys. Res., 102, 9419-9429, 1997.

Slaper, H., H. A. J. M. Reinen, M. Blumthaler, M. Huber, and F. Kuik, Comparing ground-level spectrally resolved solar UV measurements using various instruments: A technique resolving effects of wavelength shift and slit width, Geophys. Res. Lett., 22, 2721-2724, 1995.

Stamnes, K., and P. Conklin, A new multi-layer discrete ordinate approach to radiative transfer, J. Quant. Spectrosc. Rad. Trans., 37(3), 272-282, 1984

Stamnes, K., S. C. Tsay, W. Wiscombe, and K. Jayaweera, A numerically stable algorithm for discrete-ordinate-method radiative transfer in multiple scattering and emitting layered media, Appl. Opt., 27, 2502-2509, 1988.

Stammes, P., D. M. Stam, W. M. F. Wauben, and F. Kuik, Simulation and interpretation of atmospheric UV-VIS spectra using the DAK radiative transfer model, in Polar Stratospheric Ozone, edited by J. Pyle, N. Harris, and G. Amanatidis. pp. 839-844. Air Pollut. Res. Rep. 56, Eur. Comm., Brussels, 1996.

Van de Hulst, H. C., Multiple Light Scatterng, Tables, Formulas and Applications, vol. 2, Academic, San Diego, Calif., 1980.

Van Hoosier, M. E., The ATLAS-3 solar spectrum, available via anonymous $\mathrm{ftp}$ (ftp://susim.nrl.navy.mil/pub/atlas3), 1996.

Wang, P., and J. Lenoble, Comparison between measurements and modelling of UV-B irradiance for clear sky: A case study, Appl. Opt., 33, 3964-3971, 1994.

Weihs, P., and A. R. Webb, Accuracy of spectral UV model calculations, 1 , Consideration of uncertainties in input parameters, $J$. Geophys. Res., 102, 1541-1550, 1997a.

Weihs, P., and A. R. Webb, Accuracy of spectral UV model calculations, 2, Comparison of UV calculations with measurements, J. Geophys. Res., 102, 1551-1560, $1997 \mathrm{~b}$.

World Meteorological Organization (WMO), Report of the WMO meeting of experts on UV-B measurements, data quality and standardization of UV-indices, WMO Rep. 25, Les Diablerets, Switzerland, 1994.

Zeng, J., R. L. McKenzie, K. Stamnes, M. Wineland, and J. Rosen, Measured UV spectra compared with discrete ordinates method simulations, J. Geophys. Res., 99, 23,019-23,030, 1994.

M. Blumthaler and D. Haferl, Institute of Medical Physics, University of Innsbruck, Innsbruck, Austria.

P. N. den Outer, National Institute of Public Health and the Environment, Bilthoven, The Netherlands.

O. Engelsen, NORUT Information Technology, Troms $\emptyset$, Norway.

D. Gillotay and B. Walravens, Belgian Institute for Space Aeronomy, Brussels, Belgium.

P. Weihs, Institute of Meteorology and Physics, Universitaet fuer Bodenkultur, Vienna, Austria.

A. Kylling, Norwegian Institute for Air Research, Kjeller, Norway. C. Brogniez and J. Lenoble, Université des Sciences et Technologies de Lille, Villeneuve d'Ascq, France.

T. J. Martin, and G. Seckmeyer, Fraunhofer Institute for Atmospheric Environmental Research, Kreuzeckbahnstr. 19, D-82467, Garmisch-Partenkirchen, Germany.

B. Mayer, National Center for Atmospheric Research, Boulder, CO 80307.

G. Pfister, Institute for Meteorology and Geophysics, University of Graz, Graz, Austria.

A. Ruggaber, Meteorological Institute, University of Munich, Munich, Germany.

W. M. F. Wauben and M. van Weele, Royal Netherlands Meteorological Institute, De Bilt, The Netherlands.

B. G. Gardiner, British Antarctic Survey, Cambridge, United Kingdom.

(Received March 8, 1999; revised July 28, 1999; accepted October 25, 1999.) 